\title{
Simulation-Based Research on Driver Visibility of Black-and-White Striped Vehicles
}

\author{
Pei Xie, ${ }^{1,2}$ Qing Li ${ }^{(D)},{ }^{3}$ Tong Zhu ${ }^{D},{ }^{3}$ Minghua Cao, ${ }^{3,4}$ and Runqing Zhao ${ }^{5}$ \\ ${ }^{1}$ School of Automobile, Chang'an University, Xi'an, China \\ ${ }^{2}$ Guangdong Road Transportation Affairs Center, Guangzhou, China \\ ${ }^{3}$ College of Transportation, Chang'an University, Xi'an, China \\ ${ }^{4}$ Wolfson School of Mechanical, Electrical and Manufacturing Engineering, Loughborough University, Loughborough, UK \\ ${ }^{5}$ School of Aviation, UNSW Sydney, High St, Kensington, NSW 2052, Australia \\ Correspondence should be addressed to Tong Zhu; zhutong@chd.edu.cn
}

Received 16 May 2020; Revised 27 July 2020; Accepted 14 August 2020; Published 1 September 2020

Academic Editor: Kun Wang

Copyright $\odot 2020$ Pei Xie et al. This is an open access article distributed under the Creative Commons Attribution License, which permits unrestricted use, distribution, and reproduction in any medium, provided the original work is properly cited.

\begin{abstract}
The vehicle color is considered to be a significant factor affecting driver visibility. The primary objective of this study is therefore to determine the impact of black-and-white striped vehicles (BWVs) on driver visibility through simulation-based experiments. In these experiments, subjects were asked to perform front and rear target identification tasks under daylight and twilight conditions. Then, a 2 (lighting conditions) $\times 2$ (vehicle size) $\times 5$ (vehicle color) analysis of variance was conducted for each task. Under the front identification scenario, the main factors affecting visibility were found to be lighting conditions, vehicle size, vehicle color, and the interactions between these factors. Under the rear identification scenario, lighting conditions and vehicle color were found to be the main factors. The results of this study demonstrate that driver visibility of BWVs is poorer than that of other colors of vehicles and that BWV visibility is susceptible to lighting conditions.
\end{abstract}

\section{Introduction}

Although a human perceptual system consists of all sensory modalities functioning simultaneously $[1,2]$, vision is more essential for enabling drivers to perceive objects, make judgments, and generate avoidance behaviours accordingly [3]. In previous road safety studies, poor visibility has always been identified as a crucial factor leading to a higher accident rate [4-8]. An object's visibility is determined by its size, lighting conditions, and color difference [9]. Generally, an obvious color difference can lead to an eligible visibility $[10,11]$. Previous studies have verified that bright colors help to improve the detection distance for traffic signs, automobiles, and cyclists $[12,13]$. Furthermore, the lighting condition and vehicle size were considered as the affecting factors to drivers' observation as well as speeding performance $[14,15]$.

In recent years, vehicles with striped bodies have been proposed as a measure to draw people's attention, and car- hailing services in several Chinese cities have applied this approach. These striped cars (and buses) are painted with black and white stripes across the entire vehicle body. Although these vehicles may seemingly look fashionable, the stripes actually have a camouflage effect that causes their visibility to degrade as their "zebra stripes" are believed to make it more difficult to discern the vehicle, especially under poor lighting conditions [16]. Hence, the effect of black-andwhite striped vehicles (BWVs) on driver visibility deserves further investigation.

Previous studies have demonstrated the influence of vehicle color on driver visibility and response time. Nathan (1969) showed that the color of a vehicle, especially that of the rear end, has an important effect on the visibility and proposed several suggestions concerning vehicle colors, particularly for semitrucks, but these suggestions have not been adopted as laws. In a simulation-based study, vehicles in different colors under different daytime lighting conditions were shown to participants and their vehicle 
identification response times were measured and analyzed, demonstrating that there were significant differences in the response time according to vehicle color [17]. Moreover, a vehicle's background and lighting conditions deeply influence its conspicuity. Generally, white vehicles are more visible at night, but yellow vehicles perform better against cloudy skies than white ones [18].

Based on much accident data and statistical analysis, many vehicle color- and accident rate-related conclusions have been proposed. A study showed that no single color was significantly safer or riskier than white [19]. However, some studies have indicated that a vehicle's color influences its crash risk [20-25]. Using probability theory and the results of a survey, Solomon and King determined that lime-yellowcolored fire engines were significantly safer than red ones. The survey indicated that the accident rate of red vehicles (15.3 accidents per 100,000 runs) is double of that of limeyellow vehicles (31.9 accidents per 100,000 runs). An analysis of Australian accident data used induced exposure methods to show a close relationship between a vehicle's color and the crash risk [24]. In general, it can be concluded that compared with white vehicles, several colors are closely linked with higher crash rates.

Many studies have demonstrated that black cars have a higher risk of involvement in accidents. An analysis of crash data in Spain [22] indicated that light-colored (i.e., white or yellow) cars were slightly less likely to be "passively involved" in crashes, with the effect observed to be strongest during daylight on open roads under less-than-ideal weather conditions. They also concluded that black cars had the worst record for passive involvement in crashes. Furness analyzed 571 crashes in Auckland, New Zealand, between April 1998 and June 1999 in which one or more occupants required hospitalization or were killed and used 588 controls in the region consisting of drivers identified by cluster sampling and selected at random. The authors found that silver cars were half as likely to be involved in crashes resulting in serious injury as white cars, and that brown, black, and green cars were roughly twice as likely to be involved in serious injury crashes as white cars [21]. Newstead and D'Elia [20] studied the relationship between accidents and vehicle color in Victoria and West Australia. Seventeen different vehicle colors were investigated under daylight and twilight lighting conditions. The crash risk of blue vehicles in daylight was reported to be lower than that of black, grey, silver, and red vehicles. Under twilight conditions, black vehicles again had the highest risk with a $5 \%$ significance level.

In summary, many previous studies have attempted to explore the relationship between vehicle color and visibility, as well as the relationship between vehicle color and collision rate. However, to our knowledge, few studies have investigated the driver visibility of BWVs. Therefore, in this study, a series of driving experiments were conducted in which driving simulations were used to examine driver visibility under carefully designed experimental conditions. Although driving simulators have several potential disadvantages, such as simulator sickness, simulation is still regarded as a valid approach to driver studies, as it compensates for the lack of accident data in safety investigations [26]. As color difference has been observed to have a more significant impact on visibility under low light conditions [9], lighting conditions were taken as one of the experimental variables.

The objective of our experiments was to determine the effect of BWVs on driver visibility under different lighting conditions (daylight/twilight) and vehicle type (car/bus) in a simulation-based environment. Subjects drove in a typical rural environment under daylight and twilight conditions. In the experiment, the visibility of BWVs was compared with that of vehicles in other common colors such as white, black, yellow, and red. The results of our study contribute to a better understanding of drivers' perceptions and can help to devise more practical guidelines for vehicle colors.

\section{Materials and Methods}

2.1. Participants. We recruited 27 participants from Chang'an University who had Chinese driving licenses and normal vision (or normal corrected eyesight). They were between 23 and 45 ( mean $=27.51$; standard deviation $=5.15$ ) years of age. Their average driving experience was 5.41 years, with no one having any experience with driving simulators. However, six participants (four men and two women) could not complete the experiment because they showed symptoms of simulator sickness; therefore, in total, 21 subjects (13 men and 8 women) took part in the driving experiment. The age ranged from 23 to 45 years (mean $=27.85$; standard deviation $=5.59$ ). And the average driving experience was 6.10 years. Each participant was compensated with approximately $\$ 10$ after finishing the experiment.

2.2. Apparatus. The experiment apparatus included a stationary driving simulator composed of three screen displays, a steering wheel, a gear lever, a handbrake, a brake, and an accelerator pedal. The three large screens were used to project visual scenarios with a $130^{\circ}$ field of view (see Figure 1). The operational data (speed, acceleration, etc.) and maneuvering data (gears, clutch, accelerator, brake, etc.) of the vehicle were recorded in real time by using the simulator at a data acquisition frequency of $30 \mathrm{~Hz}$, and all the obtained data were saved in the UC-win/Road software.

2.3. Experiment Design and Scenarios. In this study, each subject drove along four trails (daylight and twilight $\times$ front identification task and rear identification task, see Figure 2). In each trail, the participant was required to drive on a three-lane long straight expressway under a speed limit of $100 \mathrm{~km} / \mathrm{h}$. Different types and colors of vehicles appeared in the front/rear of the vehicle randomly while driving. For front identification task, the target vehicles appeared in front of the participant. For rear identification task, each participant was required to identify approaching vehicles using the rear view mirrors. The participants were asked to press a button (to record the time point) once they confirm a vehicle was identified. This method of measurement has been used in the previous 


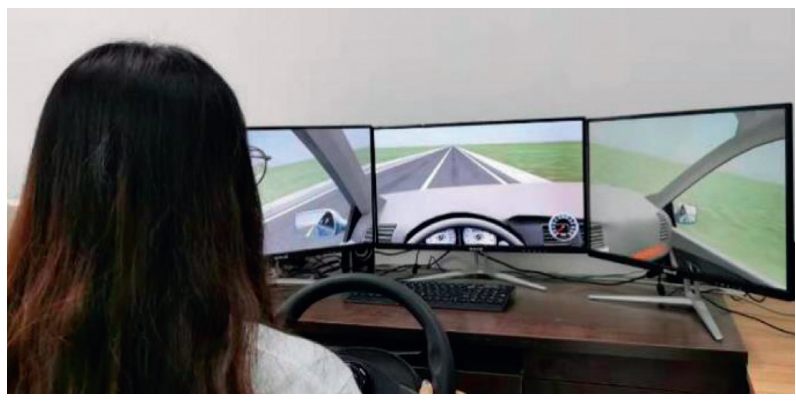

FIgURE 1: Driving simulator.

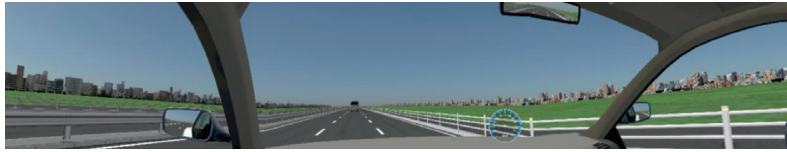

(a)

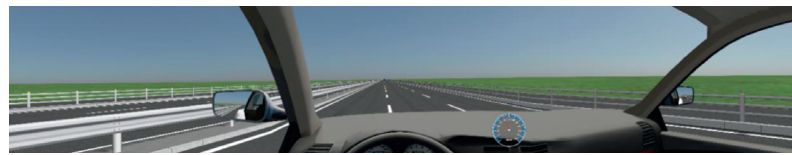

(c)

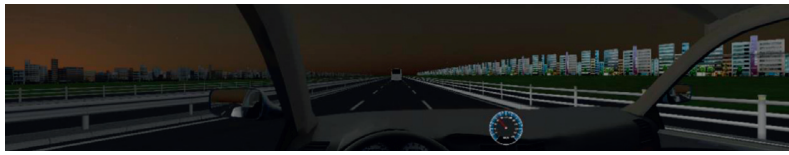

(b)

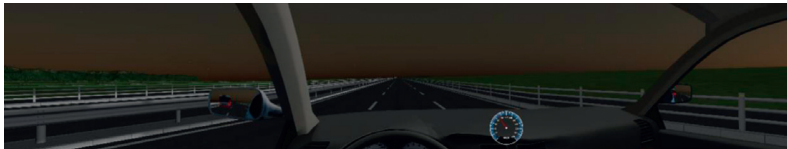

(d)

Figure 2: Experiment scenarios. (a) Front identification in daylight. (b) Front identification in twilight. (c) Rear identification in daylight. (d) Rear identification in twilight.
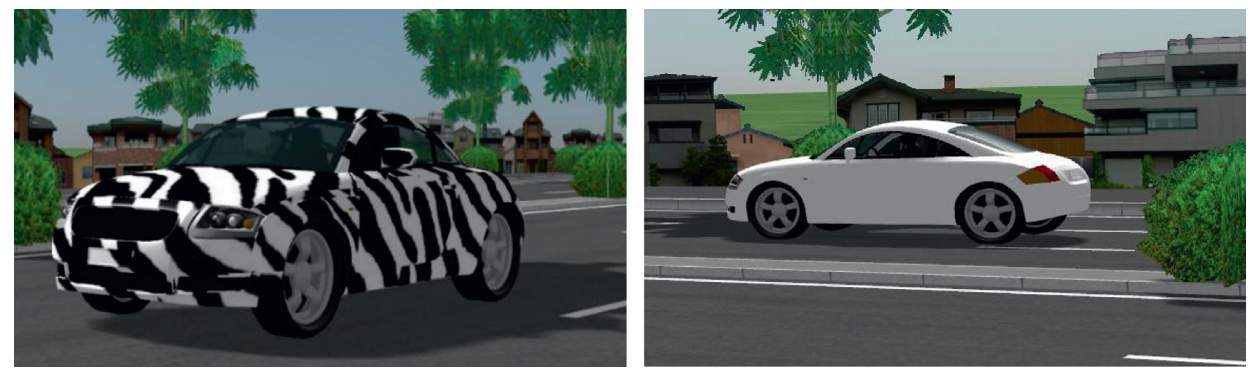

(a)
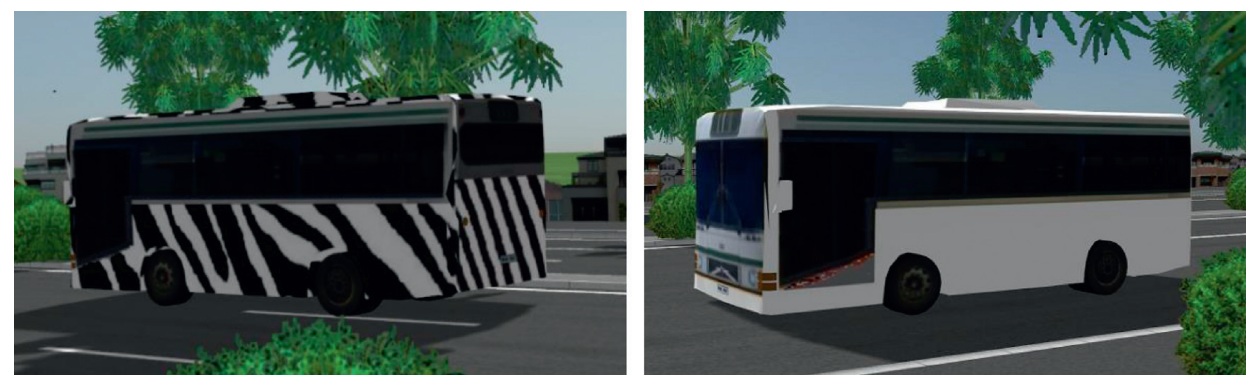

(b)

Figure 3: Vehicle models. (a) Car models. (b) Bus models.

literature [27]. The different vehicle models and colors used in the experiment are shown in Figure 3.

2.4. Procedures. Upon arrival at the laboratory, each participant was first required to complete a questionnaire (providing information such as gender, age, and driving experience) and then instructed regarding simulator operation and other necessary matters. After they have understood the process completely, they signed an approval document confirming the same. To avoid any bias, participants were not told anything that could have enabled them to guess the objective of the experiment. To familiarize them with the operation of the simulator, participants were 
allowed to use the simulator for $10 \mathrm{~min}$ before the actual experiment (training phase).

After the training phase, the participants were given a 5min break, after which they began the formal experiment in a random order, in which they were required to observe all traffic rules. In each trial, the order and the time of appearance of the vehicles were varying and each participant completed four trails in a counterbalanced order. Each participant was required to take a 5-min break after finishing each scenario; the entire experiment lasted for approximately 30 minutes per participant.

2.5. Variables. The following independent and dependent variables were considered in this study.

\subsubsection{Independent Variables}

(i) Lighting conditions: both daylight and twilight conditions were set in the driving experiment

(ii) Vehicle size: a bus and a sedan car were employed as objects in the experiment

(iii) Vehicle color: five colors were used, white, black, red, yellow, and black-white striped

\subsubsection{Dependent Variables}

(i) Distance detection was considered to be the dependent variable. This represents the distance between the participant's vehicle and the target vehicle (ahead or behind) at the time that the target vehicle is confirmed. As mentioned earlier, each participant was asked to press a button as soon as they were ready to confirm the vehicle ahead of or behind them. The distance at the time of the button press was subsequently extracted from the experiment data.

\section{Results}

An analysis of variance (ANOVA) was conducted to investigate the main and interaction effects of three factors-lighting conditions, vehicle color, and vehicle size-on the dependent variable. Bonferroni correction was used for multiple comparisons. Before the ANOVA, the test results indicated that all the data were consistent in terms of normality and homogeneity of variance. The significance threshold was set to 0.05 .

\subsection{Front Target Identification}

3.1.1. Main Factors. The average front identification distances in daylight and twilight are shown in Table 1, in which there are several differences worth mentioning. The average identification distance of the striped car was far shorter than that of the cars in other colors under both daylight and twilight conditions. In the case of the bus, the identification distance of the striped and black vehicles was shorter than that of the vehicles in other colors under twilight conditions.
Table 2 shows the results of the effects of independent variables on the dependent variable in the front identification scenario. The ANOVA revealed that the following factors had significant effects on visibility: lighting conditions $\left(F_{(1,418)}=24.34, p<0.001\right)$, vehicle size $(F$ $(1,418)=24.34, p=0.015)$, and vehicle color $\left(F_{(4,415)}=21.13\right.$, $p<0.001)$. The interactions of lighting conditions $\times$ vehicle size $\times$ vehicle color, vehicle size $\times$ vehicle color, and lighting conditions $\times$ vehicle color had significant effects $(F$ $(4,400)=11.03, \quad p<0.001 ; \quad F_{(4,410)}=4.95, \quad p=0.001 ; \quad F$ $(4,410)=15.16, p=0.001)$.

3.1.2. Vehicle Color. To determine whether vehicle color had any significant effect on visibility under different lighting conditions (daylight/twilight) and vehicle size (bus/car), an ANOVA was conducted and the results revealed that under daylight conditions, vehicle color had a significant effect on driver visibility under both vehicle sizes (car/bus) $\left(F_{(4,100)}=6.30, p_{\text {bus }}<0.001 ; F_{(4,100)}=14.65, p_{\text {car }}<0.001\right)$ (see Table 3 ). The average identification distance of the white bus was the shortest (mean white bus $=590.80 \mathrm{~m}$ ) and that of the striped bus was close to that of the buses in other colors (mean $_{\text {striped bus }}=790.62 \mathrm{~m}$, mean black bus $=759.73 \mathrm{~m}$, mean yellow bus $=675.95 \mathrm{~m}$, and mean red bus $=791.19 \mathrm{~m}$ ). The visibility of the striped car was significantly different from that of the cars in other colors (mean striped car $=406.03 \mathrm{~m}$, mean black car $=654.83 \mathrm{~m}$, mean white car $=644.39 \mathrm{~m}$, mean yellow car $=669.28 \mathrm{~m}$, and mean red car $=721.14 \mathrm{~m}$ ); the average identification distance of the striped car was the shortest. Therefore, under daylight conditions, the visibility of the striped car was the poorest and that of the striped bus was no better than that of the vehicles in other colors. Under twilight conditions, the vehicle color considerably affected driver visibility under both vehicle sizes $\left(F_{(4,100)}=25.62, \quad p\right.$ bus $<0.001 ; \quad F$ $\left.(4,100)=16.58, p_{\text {car }}<0.001\right)$ (see Table 3$)$. The post hoc results in Table 3 indicate that the visibility of the striped and black buses was completely different from that of the white, yellow, and red buses $(p$ striped-white $<0.001, p$ striped-yellow $<0.001, p$ striped-red $<0.001, p$ black-white $<0.001, p_{\text {black-yellow }}<0.001$, and $p$ black-red $<0.001)$. In addition, the visibility of the striped car was very different from that of the white, yellow, red, and black cars (mean striped car $=341.54 \mathrm{~m}$, mean black car $=561.64 \mathrm{~m}$, mean white car $=662.17 \mathrm{~m}$, mean yellow $\mathrm{car}=631.14 \mathrm{~m}$, and mean red $\mathrm{car}=658.90 \mathrm{~m})$. Moreover, the visibility of the striped bus was the poorest, but similar to that of the black bus (mean striped bus $=340.96 \mathrm{~m}$ and mean black bus $=347.77 \mathrm{~m}$ ). The striped car had the shortest average identification distance $($ mean $=341.54 \mathrm{~m})$.

3.1.3. Vehicle Size. The effect of vehicle size on driver visibility under different lighting conditions (daylight/twilight) and vehicle color (striped/black/white/yellow/red) was also analyzed. Table 4 shows that there were significant differences in driver visibility between the striped car and the striped bus and the black car and the black bus under the daylight conditions $\left(F_{(1,400)}=59.31\right.$, $\left.p_{\text {striped }}<0.001 ; F_{(1,400)}=4.41, p_{\text {black }}=0.036\right)$. The average 
TABLE 1: Descriptive statistics for the front identification distance.

\begin{tabular}{|c|c|c|c|c|}
\hline Lighting conditions & Vehicle size & Vehicle color & Average (m) & $\mathrm{SD}$ \\
\hline \multirow{10}{*}{ Daylight } & \multirow{5}{*}{ Car (small) } & Striped & 406.03 & 178.43 \\
\hline & & Black & 654.83 & 163.95 \\
\hline & & White & 644.39 & 176.95 \\
\hline & & Yellow & 669.28 & 130.03 \\
\hline & & Red & 721.14 & 32.09 \\
\hline & \multirow{5}{*}{ Bus (large) } & Striped & 790.62 & 188.13 \\
\hline & & Black & 759.73 & 133.67 \\
\hline & & White & 590.80 & 204.93 \\
\hline & & Yellow & 675.95 & 151.81 \\
\hline & & Red & 791.19 & 87.62 \\
\hline \multirow{10}{*}{ Twilight } & \multirow{5}{*}{ Car (small) } & Striped & 341.54 & 100.36 \\
\hline & & Black & 561.64 & 210.30 \\
\hline & & White & 662.17 & 108.46 \\
\hline & & Yellow & 631.14 & 162.80 \\
\hline & & Red & 658.90 & 148.43 \\
\hline & \multirow{5}{*}{ Bus (large) } & Striped & 340.96 & 203.19 \\
\hline & & Black & 347.77 & 207.55 \\
\hline & & White & 708.33 & 204.78 \\
\hline & & Yellow & 753.07 & 135.10 \\
\hline & & Red & 698.27 & 171.51 \\
\hline
\end{tabular}

TABLe 2: Main and interaction effects for front identification distance.

\begin{tabular}{lcccc}
\hline Independent variables and interactions & DF & $F$ & $p$ value & Partial eta-squared \\
\hline Lighting conditions & 1,418 & 24.34 & $<0.001$ & 0.057 \\
Vehicle size & 1,418 & 5.96 & 0.015 & 0.015 \\
Vehicle color & 4,415 & 19.42 & $<0.001$ & 0.169 \\
Lighting conditions $\times$ vehicle size $\times$ vehicle color & 4,400 & 11.03 & $<0.001$ & 0.099 \\
Vehicle size $\times$ vehicle color & 4,410 & 4.95 & 0.001 & 0.046 \\
Lighting conditions $\times$ vehicle color & 4,410 & 15.16 & 0.001 & 0.129 \\
\hline
\end{tabular}

TABLE 3: The effects of vehicle color under the front identification scenario.

\begin{tabular}{|c|c|c|c|c|c|}
\hline & \multirow{2}{*}{ Vehicle color } & \multicolumn{2}{|c|}{ Daylight } & \multicolumn{2}{|c|}{ Twilight } \\
\hline & & Bus & Car & Bus & Car \\
\hline \multirow{11}{*}{$\begin{array}{l}\text { Post hoc } \\
p \text { value }\end{array}$} & Group $p$ value & $<0.001$ & $<0.001$ & $<0.001$ & $<0.001$ \\
\hline & Striped-black & 0.530 & $<0.001$ & 0.906 & $<0.001$ \\
\hline & Striped-white & $<0.001$ & $<0.001$ & $<0.001$ & $<0.001$ \\
\hline & Striped-red & 0.991 & $<0.001$ & $<0.001$ & $<0.001$ \\
\hline & Striped-yellow & 0.021 & $<0.001$ & $<0.001$ & $<0.001$ \\
\hline & Black-white & 0.001 & 0.818 & $<0.001$ & 0.034 \\
\hline & Black-red & 0.522 & 0.147 & $<0.001$ & 0.040 \\
\hline & Black-yellow & 0.090 & 0.751 & $<0.001$ & 0.140 \\
\hline & White-red & $<0.001$ & 0.094 & 0.862 & 0.944 \\
\hline & White-yellow & 0.085 & 0.584 & 0.440 & 0.508 \\
\hline & Red-yellow & 0.021 & 0.256 & 0.345 & 0.554 \\
\hline
\end{tabular}

*Group $p$ value is a general form of the contrast analysis, so if it is not found significant, the post hoc $p$ values of that column will not be significant either. Therefore, the post hoc $p$ values were not shown in the table. ${ }^{* *}$ Due to space limitations, the $F$-values and corresponding statistics of vehicle colors are not shown in the table.

TABLE 4: Effects of vehicle size under the front identification scenario.

\begin{tabular}{|c|c|c|c|c|c|c|}
\hline \multirow{2}{*}{ Vehicle color } & \multicolumn{3}{|c|}{ Daylight } & \multicolumn{3}{|c|}{ Twilight } \\
\hline & DF & $F$ & $p$ value & DF & $F$ & $p$ value \\
\hline Striped & 1,400 & 59.31 & $<0.001$ & 1,400 & $<0.001$ & 0.991 \\
\hline Black & 1,400 & 4.41 & 0.036 & 1,400 & 18.34 & $<0.001$ \\
\hline White & 1,400 & 1.15 & 0.284 & 1,400 & 0.85 & 0.356 \\
\hline Yellow & 1,400 & 0.02 & 0.894 & 1,400 & 5.96 & 0.015 \\
\hline Red & 1,400 & 1.97 & 0.161 & 1,400 & 0.62 & 0.431 \\
\hline
\end{tabular}


identification distance of the striped car was shorter than that of the striped bus (mean ${ }_{\mathrm{car}}=406.03 \mathrm{~m}$; mean $_{\text {bus }}=790.62 \mathrm{~m}$ ), and the average identification distance of the black car was also shorter than that of the black bus $\left(\right.$ mean $_{\text {car }}=654.83 \mathrm{~m}$; mean $\left._{\text {bus }}=759.73 \mathrm{~m}\right)$. This was also the case for the visibility between the yellow car and the yellow bus, and between the black car and the black bus under twilight conditions $\left(F_{(1,400)}=5.96, \quad p\right.$ yellow $=0.015 ; \quad F$ $\left.(1,400)=18.34, p_{\text {black }}<0.001\right)$ (see Table 4$)$. The descriptive statistics in Table 1 demonstrate that under daylight conditions, the average identification distance of the yellow car was shorter than that of the yellow bus (mean car $=631.14 \mathrm{~m}$; mean $_{\text {bus }}=753.07 \mathrm{~m}$ ), but the average identification distance of the black bus was shorter than that of the black car (mean bus $=347.77 \mathrm{~m}$; mean ${ }_{\text {car }}=561.64 \mathrm{~m}$ ). Therefore, under daylight conditions, the visibility of the striped and black buses was better than that of the cars in the same colors. Under twilight conditions, the visibility of the black car was greater than that of the black bus.

3.1.4. Lighting Conditions. The result of the effect of lighting conditions on driver visibility under different vehicle sizes (bus/car) and colors (striped/black/white/yellow/red) is shown in Table 5. The visibility of striped, black, and white buses under daylight conditions was significantly different from that under twilight $\left(F_{(1,400)}=81.07, p_{\text {striped }}<0.001 ; F\right.$ $\left.(1,400)=68.05, p_{\text {black }}<0.001 ; F_{(1,400)}=5.54, p_{\text {white }}=0.019\right)$. The average identification distance of striped and black buses was longer under daylight conditions than under twilight conditions (mean striped-daylight $=790.62 \mathrm{~m}$, mean stripedtwilight $=340.96 \mathrm{~m}$; mean black-daylight $=759.73 \mathrm{~m}$, mean blacktwilight $=347.77 \mathrm{~m}$ ). In other words, the visibility of buses was greater under daylight than that under twilight, whereas the cars showed no significant differences in visibility between daylight and twilight.

(1) The Interaction Effects of Vehicle Size, Lighting Conditions and Vehicle Colors. Figure 4 depicts the interaction effects of vehicle size and color on visibility. When the vehicle size was decreased from large to small (bus to car), the average identification distance of striped, red, and yellow vehicles shortened, that of the black vehicle lengthened, and that of the white vehicle essentially remained unchanged. When an analysis of variance (ANOVA) was conducted, the results revealed that the relationship of $\mathrm{BWV}$ size (bus or car) to visibility was statistically significant $\left(F_{(1,410)}=21.34\right.$, $p<0.001)$. That is, the visibility of BWVs was affected by vehicle size with the bus having better visibility.

We also investigated the interaction effects of lighting conditions and vehicle color with the results shown in Figure 5. An ANOVA was carried out to test whether the lighting conditions significantly affected driver visibility. The ANOVA results showed that lighting conditions affected the visibility of the striped, black, and red vehicles, reflecting a statistically significant relationship $\left(F_{(1,410)}=44.11, p\right.$ striped $<0.001 ; F_{(1,410)}=42.58, p_{\text {black }}<0.001 ; F_{(1,410)}=4.02, p$ red $=0.046)$. With increasing brightness of light, the average identification distance of the striped, black, and red vehicles
TABLE 5: Effects of lighting conditions under the front identification scenario.

\begin{tabular}{lcccccc}
\hline \multirow{2}{*}{ Vehicle color } & \multicolumn{3}{c}{ Bus } & & \multicolumn{3}{c}{ Car } \\
& DF & $F$ & $p$ value & DF & $F$ & $p$ value \\
\hline Striped & 1,400 & 81.07 & $<0.001$ & 1,400 & 1.67 & 0.197 \\
Black & 1,400 & 68.05 & $<0.001$ & 1,400 & 3.48 & 0.063 \\
White & 1,400 & 5.54 & 0.019 & 1,400 & 0.13 & 0.722 \\
Yellow & 1,400 & 2.39 & 0.123 & 1,400 & 0.58 & 0.445 \\
Red & 1,400 & 3.46 & 0.064 & 1,400 & 1.55 & 0.213 \\
\hline
\end{tabular}

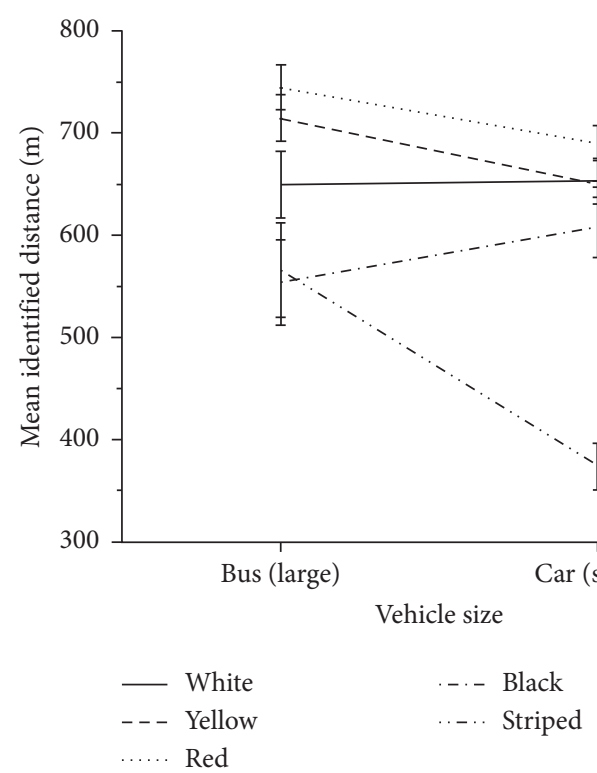

FIGURE 4: Interaction effects of vehicle size and vehicle color.

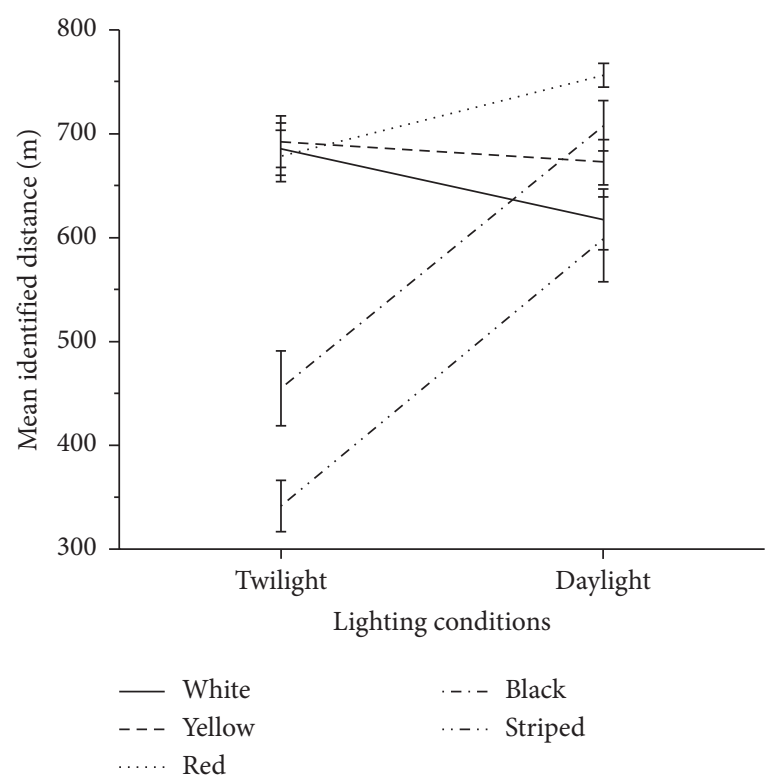

FIGURE 5: Interaction effects of lighting conditions and vehicle color. 
increased, while that of the white vehicles decreased and that of yellow vehicles remained the stable. It is also worth noting that the visibility of the white vehicles was greater under twilight conditions.

\subsection{Rear Target Identification}

3.2.1. Main Factors. The average rear identification distances under daylight and twilight conditions are shown in Table 6. There are several important findings worth mentioning. For example, under daylight conditions, the average identification distance of the yellow bus was similar to that of the yellow car, while that of the striped bus was different than that of the striped car (mean yellow bus $=186.77 \mathrm{~m}$, mean yellow $\mathrm{car}=189.22 \mathrm{~m}$, mean striped bus $=181.32 \mathrm{~m}$, and mean striped car $=72.62 \mathrm{~m}$ ). Under twilight conditions, the average identification distances of the yellow bus and the yellow car were similar, as were those of the striped bus and the striped car (mean yellow bus $=131.44 \mathrm{~m}$, mean yellow car $=129.45 \mathrm{~m}$, mean striped bus $=73.20 \mathrm{~m}$, and mean striped car $=78.91 \mathrm{~m}$ ).

The major results describing the effects of independent variables on the dependent variable in the rear identification scenarios are shown in Table 7 . The ANOVA revealed that lighting conditions $\left(F_{(1,400)}=71.03, p<0.001\right)$ and vehicle color $\left(F_{(4,400)}=7.09, p<0.001\right)$ had significant effects on driver visibility, whereas vehicle size did not show any impacts. The interactions of the independent variables, i.e., lighting conditions $\times$ vehicle color $\left(F_{(4,410)}=3.18, p=0.014\right)$ and lighting conditions $\times$ vehicle size $\times$ vehicle color $(F$ $(4,410)=2.71, p=0.030)$, had significant effects on driver visibility. However, visibility was not affected by the interaction between vehicle size and vehicle color $\left(F_{(4,410)}=2.13\right.$, $p=0.076>0.05)$.

3.2.2. Vehicle Color. Table 8 reveals the various effects of vehicle color on driver visibility under different lighting conditions (daylight/twilight) and vehicle size (bus/car). Under daylight conditions, vehicle color significantly affected driver visibility $\left(F_{(4,100)}=2.53, \quad p\right.$ bus $=0.040 ; \quad F$ $\left.(4,100)=11.42, p_{\text {car }}<0.001\right)$ for both vehicle sizes (bus and car). The visibility of the striped car was significantly different from that of the white, yellow, red, and black cars $(p$ striped-white $<0.001, p$ striped-yellow $<0.001, p$ striped-red $<0.001$, $p$ striped-black $<0.001)$. The average identification distance of the white bus was the shortest among buses (mean$=153.66 \mathrm{~m}$ ) and that of the striped bus was poor, but similar to that of the black bus (mean striped $=181.32 \mathrm{~m}$, mean black $=190.75 \mathrm{~m}$ ). The average identification distance of the striped car was the shortest among all vehicles (mean$=72.62 \mathrm{~m}$ ). Therefore, under daylight conditions, the visibility of the striped car was the poorest. Under twilight conditions, vehicle color did not show any significant effect on visibility for both vehicle sizes (bus, car) $\left(F_{(4,100)}=1.95, p\right.$ bus $\left.=0.102 ; F_{(4,100)}=1.70, p_{\text {car }}=0.149\right)$, although the visibility of the striped and black buses was poor and the visibility of the striped car was the poorest (mean striped bus $=73.20 \mathrm{~m}$, mean black bus $=75.21 \mathrm{~m}$; mean striped car $=78.91 \mathrm{~m})$.
Table 6: Descriptive statistics for the rear identification distance.

\begin{tabular}{lcccc}
\hline $\begin{array}{l}\text { Lighting } \\
\text { conditions }\end{array}$ & $\begin{array}{c}\text { Vehicle } \\
\text { size }\end{array}$ & $\begin{array}{c}\text { Vehicle } \\
\text { color }\end{array}$ & $\begin{array}{c}\text { Average } \\
(\mathrm{m})\end{array}$ & SD \\
\hline & & Striped & 72.62 & 62.02 \\
& Car & Black & 164.56 & 55.98 \\
& White & 170.76 & 41.31 \\
& (small) & Yellow & 189.22 & 87.25 \\
& & Red & 240.21 & 121.08 \\
Daylight & Striped & 181.32 & 81.45 \\
& & Black & 190.75 & 78.59 \\
& Bus (large) & White & 153.66 & 76.31 \\
& & Yellow & 186.77 & 64.85 \\
& Red & 233.30 & 116.73 \\
\hline & Striped & 78.91 & 127.62 \\
& & Black & 137.38 & 90.65 \\
& & White & 106.00 & 66.84 \\
Twilight & Car & Yellow & 129.45 & 92.11 \\
& (small) & Red & 125.33 & 73.22 \\
& & Striped & 73.20 & 56.87 \\
& & Black & 75.21 & 64.50 \\
& & White & 112.50 & 98.09 \\
& & Yellow & 131.44 & 76.34 \\
& & Red & 89.76 & 52.66 \\
\hline & & &
\end{tabular}

3.2.3. Vehicle Size. The effects of vehicle size on visibility under different lighting conditions (daylight/twilight) and vehicle colors (striped/black/white/yellow/red) were investigated using ANOVA with the results reported in Table 9. The striped bus and car exhibited striking differences in visibility under daylight conditions $\left(F_{(1,400)}=18.26\right.$, $p<0.001<0.001)$. The average identification distance of the striped car was shorter than that of the striped bus (mean car $=72.62 \mathrm{~m}$; mean bus $=181.32 \mathrm{~m}$ ). Moreover, the visibility of the black bus was different from that of the black car under twilight conditions $\left(F_{(1,400)}=5.97, p=0.015\right)$, and the average identification distance of the black bus was shorter than that of the black car (mean bus $=75.21 \mathrm{~m}$, mean $\mathrm{car}=137.38 \mathrm{~m}$ ). In conclusion, the visibility of the BWVs was affected by the vehicle's size; thus, the striped bus was easier to identify under daylight conditions. Under twilight, the visibility of the black car was, surprisingly, greater than that of the black bus.

3.2.4. Lighting Conditions. The effects of lighting conditions on visibility under different vehicle sizes (bus/car) and colors (striped/black/white/yellow/red) were analyzed, and the results are presented in Table 10 . The visibility of the striped, black, yellow, and red buses was affected by lighting conditions $\left(F_{(1,400)}=18.07, p_{\text {striped }}<0.001 ; F_{(1,400)}=20.64, p\right.$ black $<0.001 ; F_{(1,400)}=4.73, p_{\text {yellow }}=0.030 ; F_{(1,400)}=31.85, p$ red $<0.001)$, as was the visibility of white, yellow, and red cars $\left(F_{(1,400)}=6.48, p_{\text {white }}=0.011 ; F_{(1,400)}=5.52, p_{\text {yellow }}=0.019\right.$; $\left.F_{(1,400)}=20.40, p_{\text {red }}<0.001\right)$. As expected, vehicle visibility under daylight conditions was greater than under twilight conditions, regardless of whether the vehicle was a bus or a car.

(1) The Interaction Effects of Vehicle Size, Lighting Conditions and Vehicle Colors. Next, the interaction effects of vehicle 
TABLe 7: Main and interaction effects under the rear identification scenario.

\begin{tabular}{lcccc}
\hline Independent variables and interactions & DF & $F$ & $p$ value & Partial eta-squared \\
\hline Lighting condition & 1,418 & 71.03 & $<0.001$ & 0.145 \\
Vehicle size & 1,418 & 0.021 & 0.885 & $<0.001$ \\
Vehicle color & 4,415 & 7.09 & $<0.001$ & 0.064 \\
Lighting condition $\times$ vehicle size $\times$ vehicle color & 4,400 & 2.71 & 0.030 & 0.026 \\
Vehicle size $\times$ vehicle color & 4,410 & 2.13 & 0.076 & 0.020 \\
Lighting condition $\times$ vehicle color & 4,410 & 3.18 & 0.014 & 0.030 \\
\hline
\end{tabular}

TABLE 8: Effects of vehicle color under the rear identification scenario.

\begin{tabular}{|c|c|c|c|c|c|}
\hline \multirow{2}{*}{\multicolumn{2}{|c|}{ Vehicle color }} & \multicolumn{2}{|c|}{ Daylight } & \multicolumn{2}{|c|}{ Twilight } \\
\hline & & Bus & Car & Bus & Car \\
\hline \multicolumn{2}{|c|}{ Group $p$ value } & 0.040 & $<0.001$ & 0.102 & 0.149 \\
\hline \multirow{10}{*}{$\begin{array}{l}\text { Post hoc } \\
p \text { value }\end{array}$} & Striped-black & 0.928 & $<0.001$ & - & - \\
\hline & Striped-white & 0.078 & $<0.001$ & - & - \\
\hline & Striped-red & 0.455 & $<0.001$ & - & - \\
\hline & Striped-yellow & 0.010 & $<0.001$ & - & - \\
\hline & Black-white & 0.094 & 0.799 & - & - \\
\hline & Black-red & 0.512 & 0.002 & - & - \\
\hline & Black-yellow & 0.012 & 0.312 & - & - \\
\hline & White-red & 0.306 & 0.005 & - & - \\
\hline & White-yellow & 0.393 & 0.449 & - & - \\
\hline & Red-yellow & 0.062 & 0.038 & - & - \\
\hline
\end{tabular}

${ }^{*}$ Group $p$ value is a general form of the contrast analysis, so if it is not found significant, the post hoc $p$ values of that column will not be significant either. Therefore, the post hoc $p$ values were not shown in the table. ${ }^{* *}$ Due to space limitations, the $F$-values and the corresponding statistics of vehicle colors are not shown in the table.

TABle 9: Effects of vehicle size under the rear identification scenario.

\begin{tabular}{lcccccc}
\hline \multirow{2}{*}{ Vehicle color } & \multicolumn{3}{c}{ Daylight } & \multicolumn{3}{c}{ Twilight } \\
& DF & $F$ & $p$ value & DF & $F$ & $p$ value \\
\hline Striped & 1,400 & 18.26 & $<0.001$ & 1,400 & 0.05 & 0.823 \\
Black & 1,400 & 1.06 & 0.304 & 1,400 & 5.97 & 0.015 \\
White & 1,400 & 0.45 & 0.502 & 1,400 & 0.07 & 0.799 \\
Yellow & 1,400 & 0.01 & 0.923 & 1,400 & 0.01 & 0.937 \\
Red & 1,400 & 0.07 & 0.786 & 1,400 & 1.96 & 0.163 \\
\hline
\end{tabular}

TABLE 10: Effects of lighting conditions under the rear identification scenario.

\begin{tabular}{lcccccc}
\hline \multirow{2}{*}{ Vehicle color } & \multicolumn{3}{c}{ Bus } & & \multicolumn{3}{c}{ Car } \\
& DF & $F$ & $p$ value & DF & $F$ & $p$ value \\
\hline Striped & 1,400 & 18.07 & $<0.001$ & 1,400 & 0.06 & 0.805 \\
Black & 1,400 & 20.64 & $<0.001$ & 1,400 & 1.14 & 0.286 \\
White & 1,400 & 2.62 & 0.106 & 1,400 & 6.48 & 0.011 \\
Yellow & 1,400 & 4.73 & 0.030 & 1,400 & 5.52 & 0.019 \\
Red & 1,400 & 31.85 & $<0.001$ & 1,400 & 20.40 & $<0.001$ \\
\hline
\end{tabular}

size and vehicle color on driver visibility were analyzed, and the results are shown in Figure 6. When the vehicle was changed from a bus to a car, the identification distance of the black, white, and red vehicles increased, whereas it decreased for BWVs and remained the same for yellow vehicles. When an ANOVA was conducted, the results revealed that the visibility of BWVs was significantly affected by vehicle size ( $F$ $(1,410)=6.57, p=0.011)$. In other words, no matter how strong the ambient light, the visibility of the striped bus was higher than that of the striped car. The interaction effects of lighting conditions and vehicle color were also investigated using an ANOVA, and the results are shown in Figure 7. The results demonstrate that the visibilities of all five color vehicles were affected by lighting conditions $\left(F_{(1,410)}=7.68, p\right.$ striped $=0.006 ; F_{(1,410)}=15.08, p_{\text {black }}<0.001 ; F_{(1,410)}=49.45$, $p_{\text {red }}<0.001 ; F_{(1,410)}=9.81, p_{\text {yellow }}=0.002 ; F_{(1,410)}=8.31, p$ white $=0.004)$. The visibility of the striped, black, white, yellow, and red vehicles increased with increasing light intensity.

\section{Discussion}

The above results demonstrate that the color of a vehicle has a significant impact on the vehicle detection distance. The results are in accordance with those obtained in earlier studies [11]. Furthermore, we can conclude that it is more difficult for drivers to detect BWVs than vehicles in other colors under twilight conditions. By contrast, in daylight, striped bus has approximately the same visibility as black bus, while striped cars cause worse visibility than vehicles in other colors. However, previous studies indicated that brightly colored vehicles had better visibility than dark ones $[13,28,29]$. According to the results of this paper, it might make more sense for us to consider a BWV as the dark one.

At this point, discussing several aspects of visual attention theory might be helpful in interpreting our results. The visual attention theory suggests that humans focus on an object by combining top-down and bottom-up approaches $[30,31]$. The bottom-up approach means that an object can be detected using differences distinguished from its ambient environment due to its physical features [10,32]. Salience is one of the determinants of sensation and is affected by the color difference between the observed target and background [30]. It is likely for this reason that the visibility of BWVs was found to be poor under both daylight and twilight conditions, as their "zebra stripes" blend in easily with their surroundings. Some evolutionary studies may provide evidence in support of this hypothesis: a Fourier analysis of zebra stripes showed spatial frequencies in the pattern that were unlikely to be present so strongly in their natural background scenes [33]. A similar analysis of tiger stripes showed that the distribution of spatial frequencies was similar to that in a typical background scene. If stripes 


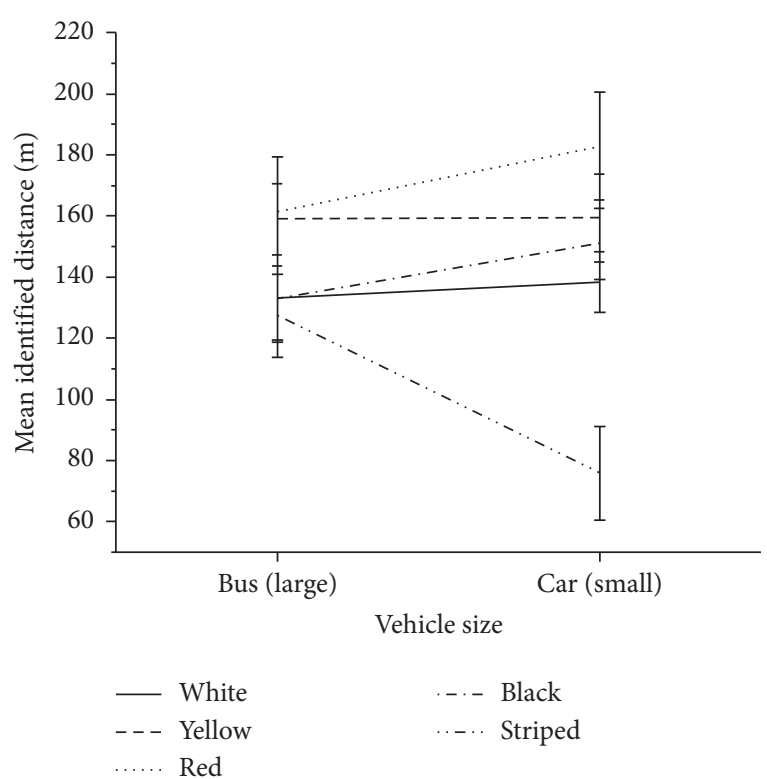

FIgURE 6: Interaction effects of vehicle size and vehicle color.

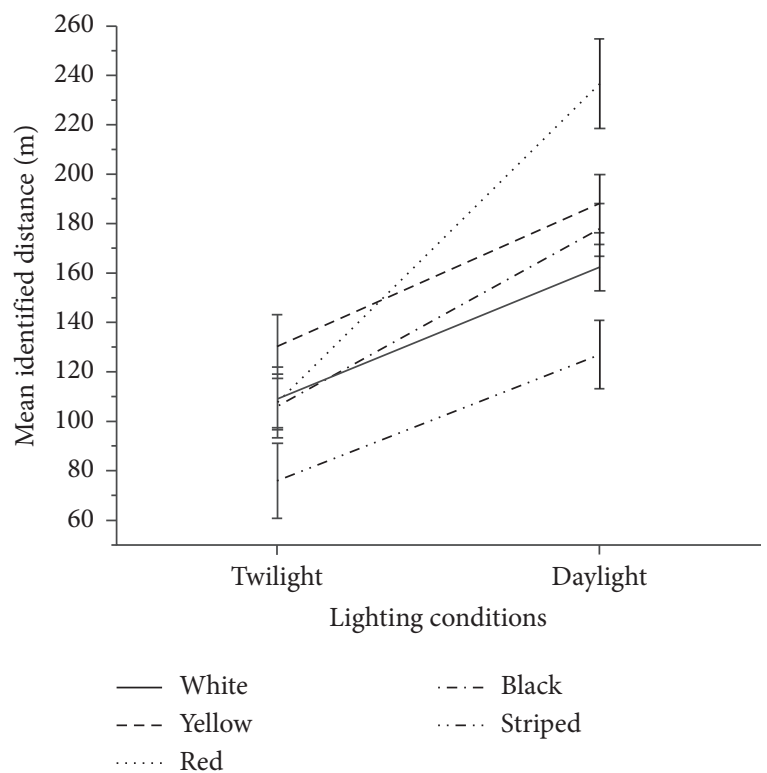

Figure 7: Interaction effects of lighting conditions and vehicle color.

do have negative effects on driver visibility, visual attention theory could help explain the poor visibility observed for BWVs in this study. Therefore, colored stripes should probably not be adopted in traffic facilities and vehicles.

Moreover, BWVs do not appear to help drivers at all in perceiving other vehicles through the top-down approach, as this perception is a knowledge-driven process depending on the level of expectancy. Although the striped car in this study is partially white, its visibility is significantly lower than that of black cars. This result may indicate that a knowledge-driven mechanism is in operation during a driver's detection of cars. Accordingly, BWVs on the road may sometimes conflict with drivers' expectations, meaning that it is possible for drivers to see the vehicle, but they may not perceive it as one. Indeed, expectations can lead to delayed detection, as was observed to be the case when objects are different than expected [34]. This indicates that unfamiliar shapes should be used as sparingly as possible on roads. Another marked result obtained in this study is that the visibility of the black bus was worse than that of the black car; this was the only colored bus whose visibility was worse than that of its equivalent color car. Normally, the larger the object is, the better the visibility it has when only depending on sensory conspicuity [11]. As a result, we can only explain this observation as being rooted in a knowledge-driven process: black buses are rare in daily life, so a bus in this color is beyond drivers' usual expectations.

In the literature, twilight is always considered an adverse visual condition for traffic safety. In this study, twilight was found to deteriorate the visibility of black vehicles in the front identification scenario (Figure 5) and that of nearly all vehicles in the rear identification scenario (Figure 7). The visibility of the striped bus was also considerably affected under twilight conditions (Figures 5 and 7), with a far lower visibility than the white bus. These results are consistent with previous studies and might account for the higher accident rate observed under twilight conditions [35] because under low-light conditions, drivers bear a heavier visual load in identifying targets in the environment [36]. Additionally, under twilight conditions, drivers are in the process of visual dark adaptation, entailing the transfer of work between rod and cone cells in the eye [37].

In conclusion, although many studies have touched upon the correlation between vehicle color and crash rate, studies investigating the visibility of BWVs' are fairly rare. In our study, the visibility of striped cars was observed to be worse than that of black cars, thereby possibly increasing accident rates in comparison to other color vehicles. Moreover, the visibility of the evaluated vehicles was susceptible to lighting conditions. It could be inferred from the results that the visual mechanism of the striped cars depended not only on the bottom-up approach but also on the top-down approach. Our research is thus significant in that the results from the driving simulations could be used as reference for automobile color design and criteria formulation. At the same time, the findings of this research could be used as a data source for confirming vision theory and explaining actual crash data.

A drawback of this study is the use of a simulator-based experiment. Although the driving simulator is considered an acceptable tool and is frequently employed in visibility examinations, an on-field test is needed to verify the results on the basis of driving simulation research. Besides, other explanatory variables that can characterize the driver's visibility can be considered in future works. Moreover, we also observed some noteworthy differences between front and rear target identification. Lighting conditions made the most vehicles poorly visible for rear identification scenarios but did the same to only a few colors of vehicles in the front identification scenarios. Perhaps, the visual mechanisms 
underlying looking forward and looking through the rearview mirror are different. However, this remains to be researched further to provide a more complete and rigorous explanation.

\section{Conclusion}

To investigate the effects of BWVs on driver visibility, a series of driving simulation-based experiments were conducted under daylight and twilight conditions. The results revealed that the visibility of the BWVs was poorer than that of white, black, yellow, and red vehicles, which is consistent with the findings in the previous studies and offers a possible explanation for much actual crash data. These findings could serve as a reference for a better understanding about drivers' visualization of striped targets and the formation of topdown and bottom-up visual attention mechanisms. The findings of the driving simulations could also be used as reference for automobile color design criteria formulation.

\section{Data Availability}

The data used to support the findings of this study are available from the corresponding author upon request.

\section{Conflicts of Interest}

The authors declare no conflicts of interest.

\section{Acknowledgments}

This research was sponsored and funded by the National Natural Science Foundation of China (Nos. 51178054 and 51108036).

\section{References}

[1] J. J. Gibson, "The Perception of the Visual World," Houghton Mifflin, Oxford, UK, 1950.

[2] J. J. Gibson, "The Senses Considered as Perceptual Systems," Houghton Mifflin, Oxford, UK, 1966.

[3] P.-E. Barjonet, "Traffic Psychology Today," Springer, Boston, MA, USA, 2001.

[4] Y. Peng, M. Abdel-Aty, Q. Shi, and R. Yu, "Assessing the impact of reduced visibility on traffic crash risk using microscopic data and surrogate safety measures," Transportation Research Part C: Emerging Technologies, vol. 74, pp. 295-305, 2017.

[5] S. Wells, B. Mullin, R. Norton et al., "Motorcycle rider conspicuity and crash related injury: case-control study," BMJ, vol. 328, no. 7444, p. 857, 2004.

[6] J. Taylor, "Important considerations missing from study of motorcycle rider conspicuity and crash related injury," BMJ, vol. 40 , pp. 5359-5379, 2015.

[7] M. Winslow and D. Makhado, Effect of Visibility on the Occurrence of Pedestrian Motor Vehicle Collisions and Injuries: A Literature Review, Transportation Research Board, Washington, DC, USA, 2005.

[8] Z. Feng, M. Yang, W. Zhang, Y. Du, and H. Bai, "Effect of longitudinal slope of urban underpass tunnels on drivers' heart rate and speed: a study based on a real vehicle experiment," Tunnelling and Underground Space Technology, vol. 81, pp. 525-533, 2018.

[9] B. W. Tansley and R. M. Boynton, "Chromatic border perception: the role of red- and green-sensitive cones," Vision Research, vol. 18, no. 6, pp. 683-697, 1978.

[10] F. L. Engel, "Visual conspicuity, directed attention and retinal locus," Vision Research, vol. 11, no. 6, pp. 563-575, 1971.

[11] P. A. Hancock, G. Wulf, D. Thom, and P. Fassnacht, "Driver workload during differing driving maneuvers," Accident Analysis \& Prevention, vol. 22, no. 3, pp. 281-290, 1990.

[12] C. Wang, W. Zhang, Z. Feng, K. Wang, and Y. Gao, "Exploring factors influencing the risky cycling behaviors of young cyclists aged 15-24 years: a questionnaire-based study in China," Risk Analysis, vol. 40, pp. 1554-1570, 2020.

[13] J. Rogé, S. Laurent, D. Ndiaye, I. Aillerie, and F. Vienne, "Does a yellow jacket enhance cyclists' sensory conspicuity for car drivers during daylight hours in an urban environment?" Safety Science, vol. 119, pp. 385-391, 2019.

[14] J. M. Wood, G. Isoardi, A. Black, and I. Cowling, "Night-time driving visibility associated with LED streetlight dimming," Accident Analysis \& Prevention, vol. 121, pp. 295-300, 2018.

[15] M. Costa, L. Bonetti, M. Bellelli, C. Lantieri, V. Vignali, and A. Simone, "Reflective tape applied to bicycle frame and conspicuity enhancement at night," Human Factors: The Journal of the Human Factors and Ergonomics Society, vol. 59, no. 3, pp. 485-500, 2017.

[16] G. D. Ruxton, "The possible fitness benefits of striped coat coloration for zebra," Mammal Review, vol. 32, no. 4, pp. 237-244, 2002.

[17] S. Dissanayake, T. Hallaq, H. Momeni, and N. Homburg, Effect of Vehicle Color and Background Visibility for Improving Safety on Rural Kansas Highways, C. Kansas State University. Transportation Education, Manhattan, KS, USA, 2015.

[18] M. Shuman, Traditional Red Colors Safety, Vol. 91, Traffic Safety, Washington, DC, USA, 1991.

[19] S. O. Owusu-Ansah, Investigation of the Relationship between Vehicle Color and Safety, University of Dayton, Dayton, $\mathrm{OH}$, USA, 2010.

[20] S. S. Solomon and J. G. King, "Influence of color on fire vehicle accidents," Journal of Safety Research, vol. 26, no. 1, pp. 41-48, 1995.

[21] S. Furness, J. Connor, E. Robinson, R. Norton, S. Ameratunga, and R. Jackson, "Car colour and risk of car crash injury: population based case control study," BMJ, vol. 327, no. 7429, p. 1455, 2003.

[22] P. Lardelli-Claret, J. De Dios Luna-Del-Castillo, J. Juan Jiménez-Moleón, P. Femia-Marzo, O. Moreno-Abril, and A. Bueno-Cavanillas, "Does vehicle color influence the risk of being passively involved in a collision?" Epidemiology, vol. 13, no. 6, pp. 721-724, 2002.

[23] D. R. Covey, "An In-Depth Analysis of the Intersection Located at United States Highway 53 and County Trunk Highway V," University of Wisconsin-Stout Menomonie, Menomonie, WI, USA, 2009.

[24] S. Newstead and A. D'Elia, "Does vehicle colour influence crash risk?” Safety Science, vol. 48, no. 10, pp. 1327-1338, 2010.

[25] H. Yang, Y. Zhang, L. Zhong, X. Zhang, and Z. Ling, "Exploring spatial variation of bike sharing trip production and attraction: a study based on Chicago's Divvy system," Applied Geography, vol. 115, Article ID 102130, 2020.

[26] C. M. Rudin-Brown, "The effect of driver eye height on speed choice, lane-keeping, and car-following behavior: results of two driving simulator studies," Traffic Injury Prevention, vol. 7, no. 4, pp. 365-372, 2006. 
[27] A. Borowsky, D. Shinar, and T. Oron-Gilad, "Age, skill, and hazard perception in driving," Accident Analysis \& Prevention, vol. 42, no. 4, pp. 1240-1249, 2010.

[28] O. B. Kylie A, C. Barry L, M. Jennifer D, and F. Andrew B, "Color and defective color vision as factors in the conspicuity of signs and signals," Human Factors: The Journal of the Human Factors and Ergonomics Society, vol. 44, pp. 665-675, 2002.

[29] L. G. Evsikova, A. E. Puisha, and A. V. Gulyakov, "Model studies of how an automobile?s color affects its visibility," Journal of Optical Technology, vol. 70, no. 6, pp. 420-422, 2003.

[30] C. Wickens, "Engineering psychology and human performance," 1992.

[31] G. R. J. Hockey, "Applied attention theory," Ergonomics, vol. 52, no. 2, pp. 270-271, 2009.

[32] F. L. Engel, "Visual conspicuity and selective background interference in eccentric vision," Vision Research, vol. 14, no. 7, pp. 459-471, 1974.

[33] D. Godfrey, J. N. Lythgoe, and D. A. Rumball, "Zebra stripes and tiger stripes: the spatial frequency distribution of the pattern compared to that of the background is significant in display and crypsis," Biological Journal of the Linnean Society, vol. 32, no. 4, pp. 427-433, 2008.

[34] G. J. Hole, L. Tyrrell, and M. Langham, "Some factors affecting motorcyclists' conspicuity," Ergonomics, vol. 39, no. 7, pp. 946-965, 1996.

[35] O. D. Alfred and S. Michael, "Differentiation of visibility and alcohol as contributors to twilight road fatalities," Human Factors: The Journal of Human Factors and Ergonomics Society, vol. 38, pp. 680-689, 1996.

[36] C. I. Lou, D. Migotina, J. P. Rodrigues et al., "Object recognition test in peripheral vision: a study on the influence of object color, pattern and shape," in Proceedings of the International Conference on Brain Informatics, pp. 18-26, Macau, China, December 2012.

[37] G. Mather, Foundations of Sensation and Perception, London, UK, 3rd edition, 2016. 